\title{
Transarterial embolization with n-butyl cyanoacrylate for the treatment of active abdominopelvic bleeding in the polytraumatized patient
}

Rafael Kiyuze de Freitas ${ }^{1 *}$, Lucas Moretti Monsignore ${ }^{1}$, Luis Henrique de Castro-Afonso ${ }^{1}$, Guilherme Seizem Nakiri ${ }^{1}$, Jorge Elias-Junior², Valdair Francisco Muglia ${ }^{2}$, Sandro Scarpelini ${ }^{3}$ and Daniel Giansante Abud ${ }^{1}$

\begin{abstract}
Purpose: An increasing number of polytraumatized patient presenting with active abdominal pelvic bleeding (APB) have been treated by endovascular selective embolization. However, reports on evaluate the efficacy, safety and complications caused by this technique have been limited. The aim of this study was to assess the safety and efficacy of embolization of APB using N-butyl cyanoacrylate glue (NBCA).

Materials and methods: Single center retrospective study, that included consecutive 47 patients presenting with traumatic APB treated by embolization with NBCA between January 2013 and June 2019. The efficacy endpoint was defined as the absence of contrast extravasation immediately after procedure and clinical stabilization in the following $24 \mathrm{~h}$ after procedure. Clinical stabilization was defined as no rebleeding after embolization or the need for a surgical approach until the patient is discharged. Safety endpoint were any technical or clinical complications related to the embolization procedure.

Results: The mean age of patients was 38.6 years (3-81), with a predominance of males (87.2\%). The major causal factor of APB being involvement in a car accident, accounting for $68 \%$ of cases. Of the 47 cases, $29.8 \%$ presented pelvic trauma and the remaining (70.2\%) presented abdominal trauma. The efficacy rate was $100 \%$, while no complications related to the procedure were observed. The mortality rate was $14.8 \%$ (7/47) due to neurologic decompensation and other clinical causes.
\end{abstract}

Conclusion: Endovascular embolization of traumatic abdominopelvic bleedings appear to be a highly safe and effective treatment, while avoiding emergent exploratory open surgeries.

Keywords: Hemorrhage, Trans-arterial embolization, Interventional radiology, Wounds and injuries

\footnotetext{
*Correspondence: rafael.freitas@usp.br; rkfreitas56@gmail.com

'Division of Interventional Radiology, Department of Radiology, Hematology

and Oncology, Medical School of Ribeirão Preto, University of São Paulo,

Avenida Bandeirantes, 3900, Monte Alegre, Ribeirão Preto, SP 14048-090,

Brazil

Full list of author information is available at the end of the article
}

\section{Springer Open}

(c) The Author(s). 2021 Open Access This article is licensed under a Creative Commons Attribution 4.0 International License, which permits use, sharing, adaptation, distribution and reproduction in any medium or format, as long as you give appropriate credit to the original author(s) and the source, provide a link to the Creative Commons licence, and indicate if changes were made. The images or other third party material in this article are included in the article's Creative Commons licence, unless indicated otherwise in a credit line to the material. If material is not included in the article's Creative Commons licence and your intended use is not permitted by statutory regulation or exceeds the permitted use, you will need to obtain permission directly from the copyright holder. To view a copy of this licence, visit http://creativecommons.org/licenses/by/4.0/. 


\section{Introduction}

Injuries due to violence and accidents, called external causes, have a great social impact because of their high prevalence and incidence (Rezende Neta et al. 2012; Whitaker et al. 1998). Trauma is the 8th leading cause of death in the world's population, and the first among the world's young population (Global Health Observatory (GHO) data 2016), thus represents a major impact factor of global public health.

About $40 \%$ of early deaths related to polytrauma patients are caused by uncontrollable bleeding related to trauma, especially when hemorrhage originates from solid organs and pelvic fractures (Papakostidis et al. 2012; Lopera 2010; Ptohis et al. 2017; Hildebrand et al. 2006). Super selective transarterial embolization (SE) of injured vessels is an adjuvant method in the treatment of trauma patients and has broadened the spectrum of care to these patients. This technique can provide hemostasis in areas of difficult surgical access, providing non-surgical management of solid visceral lesions or isolated vascular lesions and quickly stop bleeding while preserve organ's function (Ptohis et al. 2017; Wallis et al. 2010; Ierardi et al. 2016). Moreover, compared to the open surgery, embolization is associated to reduced physiological stress, reduced blood transfusions and volume resuscitation, and reduced mortality rates (Wallis et al. 2010; Ierardi et al. 2016; Coccolini et al. 2017).

The key embolic materials used in abdominalpelvic bleeding (APB) are N-butyl cyanoacrylate (NBCA), metal coils, hemostatic gelatin sponge $\left(\right.$ Gelfoam $\left.^{\circ}\right)$, Amplatzer ${ }^{\circ}$ plugs, or association between methods (Monsignore et al. 2012).

The main objective of this study was to assess the safety and efficacy of SE for traumatic APB using NBCA as a first line strategy.

\section{Materials and methods}

A single-center retrospective study that included consecutive 47 patients with blunt or perforated abdominalpelvic trauma with active bleeding as demonstrated by imaging methods and who underwent SE with NBCA, between January 2013 and June 2019. NBCA was selected as the embolic material due to its high availability, its low cost compared to other embolization materials, and the interventionists' broad experience with this material. SE was indicated in conference between surgeons and interventional radiologists which indicated a first line embolization for patients presenting with APB and that had hemodynamic instability, or failure of conservative treatment, or active bleeding on imaging examination.

The assessed variables were gender, age, causal factor of the injury, site of the bleeding, type imaging finding, embolic material used. The efficacy endpoint was defined as two post-procedure parameters: (1) the absence of contrast extravasation immediately after procedure and (2) clinical stabilization in the following $24 \mathrm{~h}$ after procedure. Clinical stabilization was defined as no rebleeding after embolization or no need for a surgical approach until the patient discharged. Safety endpoint were absence of SE related technical or clinical complications. Technical complications were embolization other arteries not associated with the bleeding and/or any SE-related hemorrhaging.

The procedure was performed by a standard percutaneous transfemoral access with a 5-F sheath. Angiography of the aorta and of the suspected vessel were performed with 5-F catheters. All procedures were done under fluoroscopy and/or roadmap technique. A microcatheter (Excelsior SL-10,Stryker; Echelon 10, Medtronic; Progreat 2.7,Terumo) was advanced over a $0.014 \mathrm{in}$. wire (Transend-Stryker, or SilverSpeed-Medtronic) in order to approach the feeding artery of the hemorrhage as closed as possible (Fig. 1). Before embolization, the microcatheter was flushed with $5 \%$ dextrose solution followed by injection of NBCA (Glubran 2; GEM Srl, Viareggio, Italy or Histoacryl ${ }^{\circ}$; B. Braun, AG, Melsungen, Germany), in a solution with ethiodized oil (Lipiodol UF; Guerbet, Villepinte, France) ranging from 1:2 to 1:5 proportion, depending on the location of the injury. The microcateter was removed 1 to 3 min after embolization in order to avoid their imprisonment. A final control angiogram was performed in order to confirm occlusion of the bleeding arteries. Categorical variables were presented as percentages.

\section{Results}

Forty-seven consecutive patients presenting with traumatic APB who underwent embolization were included in this study. The mean age of the patients in this study was 38.6 years (ranging from 3 to 81 years) with males forming $87.2 \%$ of them. The main cause of trauma was due to automobile accidents (70\% of patients). Moreover, six patients had knife wounds, eight had falls from height (scaffolding, roofs, etc.) and one had undergone trampling by cattle. Among all abdominal bleeding, 18 were in liver, nine in spleen, three in kidney, one in adrenal and two in abdominal wall. Pelvic trauma accounted for 14 cases (29.8\%). Two related to bladder rupture and the others to pelvic ring vascular lesions (rupture, stop and arterial parietal irregularity) (Table 1). Trauma was classified according to the criteria of the American Association of Trauma Surgery. In liver trauma, $23 \%$ of grade V, $54 \%$ of grade IV, $7.7 \%$ of grade III and $15.3 \%$ of grade II. The splenic traumas were divided into $12.5 \%$ grade $\mathrm{V}, 25 \%$ grade IV, $50 \%$ grade III and $12.5 \%$ grade II. Renal traumas were classified as grade IV and adrenal trauma as grade III. 


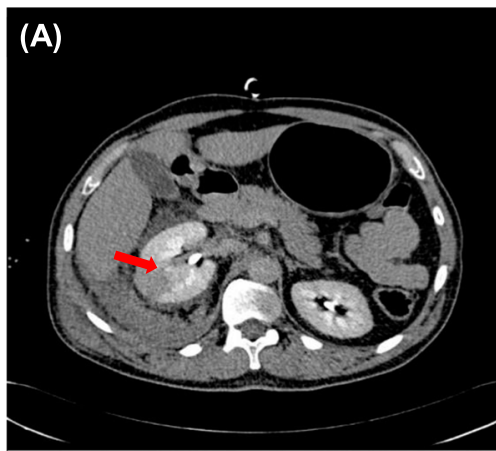

(C)

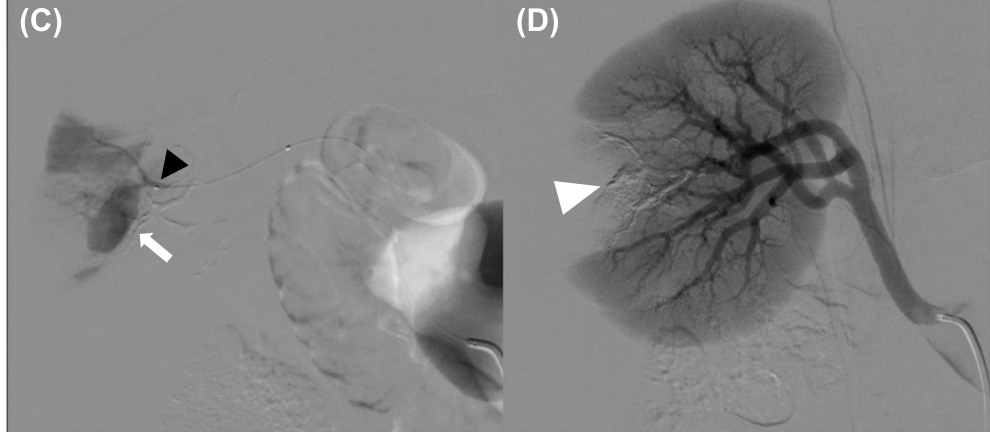

Fig. 1 (a) Computed tomography (CT) image after endovenous contrast injection, depicting contrast deposition inside the right kidney. (b) Digital subtraction angiography (DSA) with injection from right renal artery showing pseudoaneurysm (white arrow), best seen in image (c) with a DSA performed by a microcatheter (black arrow) in the segmentar renal artery. (d) After embolization, glue cast (white arrow heads) in a subtracted image in the renal territory after embolization with complete superseletiva exclusion of the injured vessel from the circulation

Table 1 Clinical data of patients

\begin{tabular}{ll}
\hline Clinical data $(\mathbf{N})$ & Total population $(\mathbf{N}=\mathbf{4 7})$ \\
\hline Age, years (median, range) & $38.6(3-81)$ \\
Male, $(\mathrm{n}, \%)$ & $41(87.2)$ \\
Region of trauma $(\mathrm{n}, \%)$ & $33(70.2)$ \\
Abdominal & $14(29.8)$ \\
Pelvic & \\
Potentially injured organs ( $\mathrm{n}, \%)$ & $18(38)$ \\
Liver & $14(29.8)$ \\
Pelvis & $9(18.9)$ \\
Spleen & $3(6.4)$ \\
Kidney & $2(4.6)$ \\
Abdominal wall & $1(2.3)$ \\
Adrenal & \\
Type of trauma $(\mathrm{n}, \%)$ & $32(68)$ \\
Automobile & $6(12.7)$ \\
Knife wounds & $8(17)$ \\
Fall from height & $1(2.3)$ \\
Others &
\end{tabular}

Ninety-seven and a half percent of the cases underwent contrast-enhanced computer tomography $(\mathrm{CT})$ and digital subtraction angiography (DSA). Only one patient did not undergo contrast-enhanced $\mathrm{CT}$ due to significant hemodynamic instability at the time of arrival at the institution, with no clinical conditions for open surgery, and a DSA was performed for diagnosis and therapy at the same time. The main CT finding was contrast extravasation $(78.2 \%$ of the cases who underwent CT) (Fig. 2) and one case of arteriovenous fistula. In the other nine cases, no findings suggestive of active bleeding were observed on CT; however, alterations of the hematimetric levels in these patients were decisive factor in the indication of DSA. In DSA, contrast extravasation, contrast stagnation, arterial blush or anomalous blush, pseudoaneurysm, vascular irregularity/stop and arteriovenous fistula were observed with contrast extravasation being the most common of them (93,6\%). In 78,2\% of the cases, APB was observed on CT and confirmed by DAS in the same topography, while in the remaining $21.8 \%$ the findings related to active bleeding were observed solely by DSA (Table 2).

All procedures were performed with NBCA as the only embolic material. In all cases, only one microcatheter was used for occlusion of the bleeding site, and only one injection of NBCA solution was necessary. Lipiodol and NBCA solutions varied from 1:2 to 1:5 (NBCA:Lipiodol), 


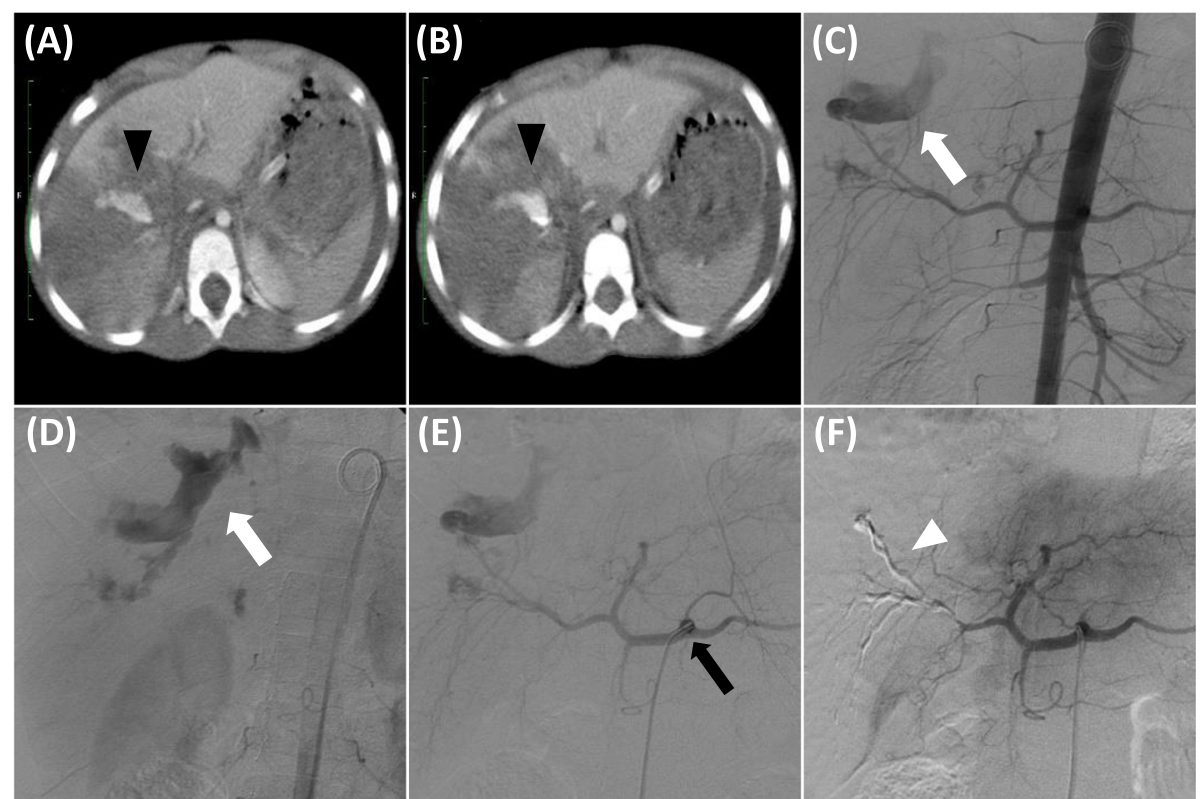

Fig. 2 (a, b) CT image arterial phase after endovenous contrast injection, depicting contrast deposition inside the right liver lobe (black arrowhead). (c, d) DSA with Pigtail cateter injection in aorta showing contrast extravasation (white arrow), seen in image (e) with a DSA performed by a Cobra 2 catheter (black arrow) in the celiac trunk. (f) After embolization, glue cast (white arrowhead) in a subtracted image in the liver territory after embolization with complete superseletiva exclusion of the injured vessel from the circulation

depending on the location and type of the lesion. In 51\% of all cases, we used a concentration of 1:3(25\%), which, in this study, was considered as standard for a fast but still well controlled propagation of the embolic liquid. In topographies which access was difficult or too distal, we used a more diluted and fluid solution 1:4 $(20 \%)$ or $1: 5$ (16.7\%) to obtain a more distal propagation of the embolic fluid. In cases in which we consider as high-flow lesions, such as arteriovenous fistulas, we used 1:2 (33, $3 \%$ ) to avoid delayed polymerization and the propagation

Table 2 Imaging data

\begin{tabular}{ll}
\hline & Total population $(\boldsymbol{N}=\mathbf{4 7})$ \\
\hline Admission $(n, \%)$ & $46(97,8)$ \\
CT & $1(2,2)$ \\
DSA & $47(100)$ \\
DSA (n, \%) & \\
CT Finding & $36(78,2)$ \\
Contrast Extravasation & $1(6,4)$ \\
Others & $9(15,4)$ \\
Without finding & \\
DSA finding & $44(93,6)$ \\
Contrast Extravasation & $3(6,4)$ \\
Others &
\end{tabular}

DSA digital subtraction angiography, CT computed tomography of embolic material to the venous side and then to nontarget organs.

We didn't observe cases of non-target vascular occlusion via inadvertent embolization, which is considered one of the most serious clinically significant NBCA complication (Monsignore et al. 2012). In cases of abdominal wall bleeding embolization, were not observed any cutaneous necrosis. In all cases embolization was performed as distal as possible to the bleeding site, and in only one case a complete arterial organ occlusion was necessary, which was in an adrenal trauma (Fig. 3). We also didn't observe vessel injuries such as spasm, dissection or perforation, microcatheter rupture and catheter entrapment.

Seven deaths (14.9\%) occurred and were caused by other conditions such as clinical decompensation (mainly related to sepsis) or brain injuries, such as intracranial hemorrhage. No death was related to the endovascular procedure. Data analysis did not identify hemorrhagic or thromboembolic complications related to the embolization.

In this series the technical success rate was $100 \%$, while no complications were observed related to the procedure (Table 3).

\section{Discussion}

Trauma is a cause of lesions in intra-abdominal solid organs and pelvic structures, affecting most patients in young adulthood, being responsible for high morbidity 

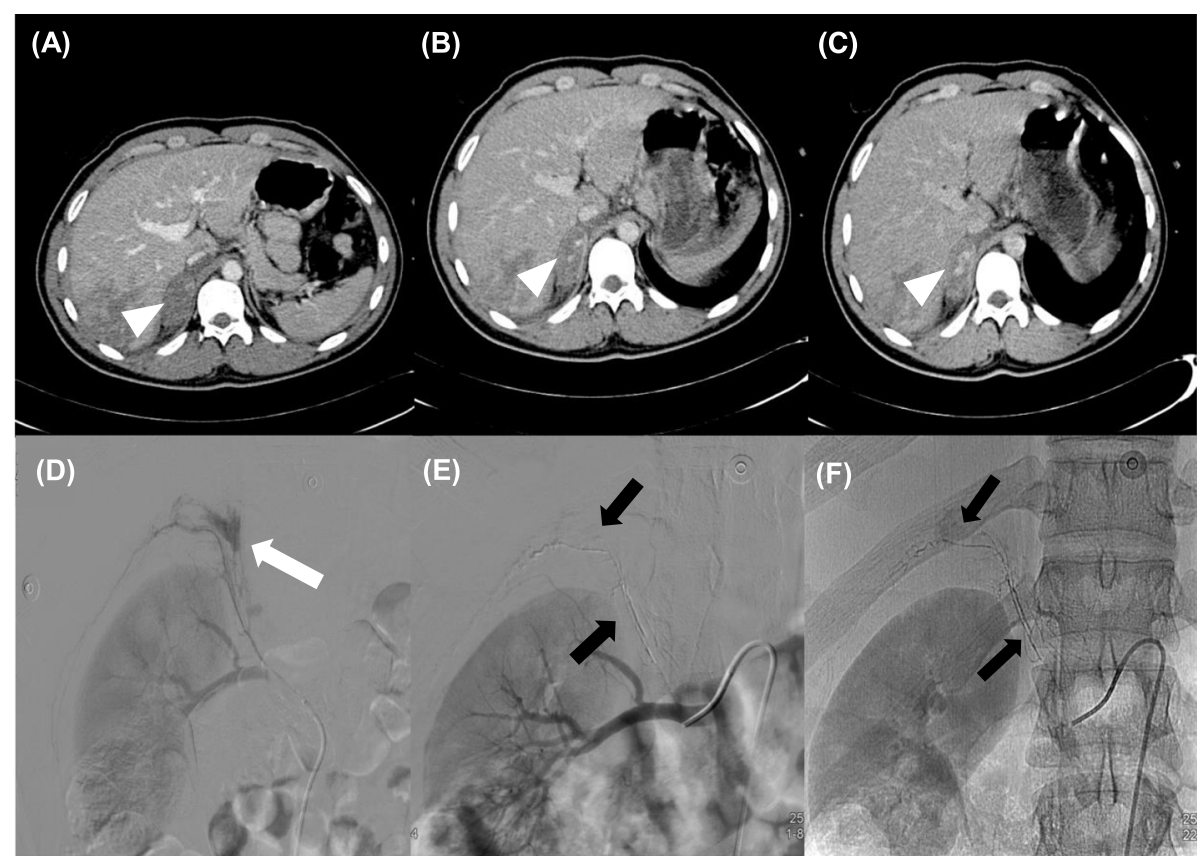

Fig. $3(\mathbf{a}, \mathbf{b}, \mathbf{c})$ CT image venous phase (a) and arterial phase (b, c) after endovenous contrast injection, depicting contrast deposition inside the right adrenal gland (white arrowhead). (d) DSA with injection right renal artery showing contrast extravasation (white arrow). (e) DSA with injection right adrenal artery showing glue cast (black arrow) in a subtracted image in the adrenal territory after embolization with complete superseletiva exclusion of the injured vessel from the circulation. (f) Subtraction image showing glue cast (black arrow)

and mortality rates (Azami-Aghdash et al. 2018; Gad et al. 2012). In agreement with other studies, these lesions are the main etiologies of acute active bleeding in abdominal and pelvic structures. Trauma has a great economic impact, being responsible for $12 \%$ of health care costs worldwide (American College of Surgeons Trauma Commite 2012).

Abdominopelvic trauma can be divided into penetrating and contused, the latter being the most common (Karamercan et al. 2008). In our study, the most frequently injured solid abdominal organ includes liver, followed by spleen, and kidney, consistently with other articles (Matthes et al. 2003; Smith et al. 2005) .

Approaches for the treatment of traumatic lesions of abdominal and pelvic structures are based on radiological findings, according to the American Association

Table 3 Procedures and results

\begin{tabular}{ll}
\hline & Total population $(\boldsymbol{N}=\mathbf{4 7})$ \\
\hline Technical Success $(n, \%)$ & $47(100)$ \\
Clinical Success $(n, \%)$ & $47(100)$ \\
Embolic material & NBCA $(100)$ \\
Complications (n, \%) & $0(0)$ \\
Mortality (n, \%) & $7(14,8)$ \\
Clinical decompensation & $4(57,1)$ \\
Brain injury & $3(42,9)$ \\
\hline
\end{tabular}

NBCA N-Butyl Cyanoacrylate for the surgery of trauma classification, and the patient's clinical condition (The ATLS Subcommittee, American College of Surgeons' Committee on Trauma, and the International ATLS working group, Chicago I 2013).

With the evolution of the technique, materials, experience of interventional radiologists, with better results and lower rates of complications, and its minimally invasive aspect, the treatment of APB by embolization has had a significant role in the emergency scenario.

Among the hepatic vascular lesions, about $85 \%$ are caused by trauma (Monsignore et al. 2012); more than $80 \%$ of the hepatic lesions related to trauma can be treated with non-surgical interventions, such as clinical/ radiological control (Petrowsky et al. 2012; Leppaniemi et al. 2011; Cherian et al. 2016). Embolization represents a significant number in non-surgical therapy, especially in patients with grade IV and V liver trauma, with high rates of success, with $97 \%$ of technical success at the end of the procedure (Ierardi et al. 2016; van der Wilden et al. 2013; Stassen et al. 2012; Monnin et al. 2008).

The management of splenic lesions presents divergences in the different trauma centers around the world, which indicates a difficulty in the management of this type of lesion, being widely considered the non-surgical treatment. In most of the reviewed studies, the splenic lesion with embolization was treated using as embolic material metal spirals and PVA particles (Wallis et al. 2010; Ierardi et al. 2016; Raikhlin et al. 2008; Wahl et al. 
2004; Hagiwara et al. 2004), in contrast to the present study, which had the NBCA glue as the embolic material of choice. The technical success rates of the main studies are high, with 89 to $95 \%$ (Ierardi et al. 2016; Wahl et al. 2004; Hagiwara et al. 2004; Wei et al. 2008; Sabe et al. 2009) of clinical success reported in the literature.

Embolization of active renal bleeding evidenced on CT is considered an adjunct treatment to the non-operative treatment of these lesions. Renal super selective embolization has great value in preserving the functionality of the remaining parenchyma, due to the poor collateral network observed in this organ (Ptohis et al. 2017). The success rates in the transarterial embolization literature are around 96\%, while the complication rates are around $8 \%$ (Ierardi et al. 2016). The most reported material in the literature for embolization in the treatment of renal trauma are metal spirals (Matthes et al. 2003), while in this study the NBCA was the embolic material of choice.

Pelvic trauma account for a large proportion of cases of trauma. Most of the treatment protocols reported in the literature in relation to pelvic trauma are based on the "Control of orthopedic damage" (Zealley and Chakraverty 2010; Hoff et al. 2002), which recommends a rapid intervention focused on bleeding control and lifesaving measures, due to the high degree of bleeding and mortality of this type of trauma. External fixation and direct surgical hemostasis are the measures initially performed in pelvic trauma, but embolization has had an increasing role in emergency hemostasis in this territory (Zealley and Chakraverty 2010). Embolization success rates are high, ranging from 85 to $100 \%$ in the literature, and similar rates are observed in this article. The main embolic agents described in the literature for this type of trauma are NBCA, PVA particles and micromoles, alone or in association, in contrast to this study in which all cases were treated with NBCA.

Adrenal lesion secondary to thoracoabdominal trauma is a very rare disease and is difficult to suspect clinically. The literature on the subject is rare, covered only by case reports (Fowler et al. 2013). Imaging exams performed at the admission of polytraumatized patients, such as CT, are helpful in the diagnosis. Treatment of this type of lesion varies with severity, and may be conservative, open surgery, or TE. This kind of treatment of adrenal trauma is rare, as well as its epidemiology; however, it can also be of high value, sparing the patient from open surgery when there is high physiological stress secondary to the trauma. The literature is not sufficiently substantiated to evaluate superiority in relation to the materials used (Fowler et al. 2013). We observed only one case of active bleeding of the adrenal gland after traumatic abdominal trauma and the NBCA was used as the embolizing agent of choice.
When all the abdominal and pelvic territories eligible for embolization of traumatic bleeding are considered, the literature outlines a wide range of embolic agents, including metal spirals, hemostatic gelatin (Gelfoam ${ }^{\odot}$ ), PVA particles and, more rarely, NBCA and non-adhesive liquid embolic agents like Onyx ${ }^{\oplus}$. The selection of embolic material has as main criterion the experience and preference of the interventional radiologist (Papakostidis et al. 2012; Lopera 2010; Wallis et al. 2010; Monnin et al. 2008).

The NBCA is an embolic agent rarely seen in the literature for the treatment of bleeding of various etiologies. In the current study, embolization performed for the treatment of trauma-related active bleeding lesions were performed with NBCA glue exclusively.

As a liquid embolic material, the NBCA has the benefit of completely occluding a vessel and/or hemorrhagic injury, which is extremely selective, rapidly prepared and used, solving the active bleeding quickly, when used by professionals trained in its manipulation.

Even though there is the possibility of non-target embolization, the NBCA is still considered of highly safety and effectiveness in the treatment of traumatic hemorrhagic lesions. As this embolizing agent does not depend on the patient's coagulation status, it can be safely be used in cases of severe coagulopathy, which is often observed in patients in the emergency room. Some interventional radiologists avoid the use of adhesive liquid embolic agents because they consider their manipulation and injection very difficult, probably due to lack of experience with the material. The main technical limitation of the use of NBCA is its manipulation. Its characteristics of polymerization, dilution with Lipiodol, injection speed, reflux control, anatomical familiarity are important aspects related to its use, and the physician should know them well to perform safe and successful procedures (Monsignore et al. 2012).

The main complications related to the use of the NBCA are the occlusion of non-target territory, either by mistaken interpretation of the anatomy, migration of embolic material, reflux of embolic material and opening of arterio-arterial anastomoses during injection, or by migration of embolic material into the venous system, which may cause pulmonary embolism or restriction of venous return (Niimi et al. 2003). The limitations of our study were the small number of patients, its retrospective nature and and the absence of a control group, although it was consistent with other reports in the literature.

\section{Conclusions}

Endovascular embolization of traumatic abdominopelvic bleedings appears to be a highly safe and effective treatment, while avoiding emergent exploratory open surgeries. 


\section{Acknowledgements}

Not Applicable.

\section{Authors' contributions}

Rafael Kiyuze de Freitas participated in the concepts of the study, he drafted and approved the manuscript; Lucas M Monsignore participated in the study concepts and design, data analysis, revision and final approval of the manuscript; Luis H de Castro Afonso, Guilherme S Nakiri, Jorge E Junior, Valdair F Muglia and Sandro Scarpelini participated in data acquisition, figures and tables edition, revision and final approval of the manuscript: Daniel G Abud concept the study, acquired data, revised critically the manuscript, and approved the final work

\section{Funding}

This study was not supported by any funding.

\section{Availability of data and materials}

All data generated or analysed during this study are included in this published article and its supplementary information files.

\section{Declarations}

\section{Ethics approval and consent to participate}

This project was approved by the ethics and research committee of the Hospital das Clínicas de Ribeirão Preto of the University of São Paulo. Approval Protocol Number: 2.499.508.

All participants, or their legal guardians, in this project have signed a free and informed consent form for the completion of the procedures.

\section{Consent for publication}

Not applicable.

\section{Competing interests}

The authors declare that they have no competing interests.

\section{Author details}

'Division of Interventional Radiology, Department of Radiology, Hematology and Oncology, Medical School of Ribeirão Preto, University of São Paulo, Avenida Bandeirantes, 3900, Monte Alegre, Ribeirão Preto, SP 14048-090, Brazil. ${ }^{2}$ Division of Abdominal Radiology, Department of Radiology, Hematology and Oncology, Medical School of Ribeirão Preto, University of São Paulo, Ribeirão Preto, Brazil. ${ }^{3}$ Division of Emergency Surgery, Department of surgery and anatomy, Medical School of Ribeirão Preto, University of São Paulo, Ribeirão Preto, Brazil.

\section{Received: 28 November 2020 Accepted: 22 March 2021}

\section{Published online: 06 May 2021}

\section{References}

American College of Surgeons - Trauma Commite. Advanced Trauma Life Suport - Manual do Curso de Alunos. $9^{\circ}$ edition. Brasel KJ, editor. Chicago, IL 606113211: Advanced Trauma Life Supportl Student Course Manual; 2012

Azami-Aghdash S, Aghaei MH, Sadeghi-Bazarghani H (2018) Epidemiology of road traffic injuries among elderly people; a systematic review and metaanalysis. Bull Emerg Trauma 6(4):279-291. https://doi.org/10.29252/beat-0604 03

Cherian M, Kalyanpur T, Murali KS, Garg A, Munde Y, Yadav A et al (2016) Safety and effectiveness of Transarterial embolization for blunt abdominal injuries: a multicenter study with review of literature. J Clin Interv Radiol 1:13-19

Coccolini F, Stahel PF, Montori G, Biffl W, Horer TM, Catena F et al (2017) Pelvic trauma: WSES classification and guidelines. World J Emerg Surg 12:1-18. https://doi.org/10.1186/s13017-017-0117-6

Fowler AM, Burda JF, Kim SK (2013) Adrenal artery embolization: anatomy, indications, and technical considerations. Am J Roentgenol 201(1):190-201. https://doi.org/10.2214/AJR.12.9507

Gad MA, Saber A, Farrag S, Shams ME, Ellabban GM (2012) Incidence, patterns, and factors predicting mortality of abdominal injuries in trauma patients. $\mathrm{N}$ Am J Med Sci 4(3):129-134. https://doi.org/10.4103/1947-2714.93889

Global Health Observatory (GHO) data. Top 10 causes of death. World Heal. Organ. 2016. Available from: https://www.who.int/gho/mortality_burden disease/causes_death/top_10/en/. [cited 2019 May 18]
Hagiwara A, Murata A, Matsuda T, Matsuda H, Shimazaki S, Scalea TM et al (2004) The usefulness of transcatheter arterial embolization for patients with blunt polytrauma showing transient response to fluid resuscitation. J Trauma - Inj Infect Crit Care. 57(2):271-277. https://doi.org/10.1097/01.TA.0000131198.791 $53.3 \mathrm{C}$

Hildebrand F, Winkler M, Van Griensven M, Probst C, Musahl V, Krettek C et al (2006) Blunt abdominal trauma requiring laparotomy: an analysis of 342 polytraumatized patients. Eur J Trauma 32(5):430-438. https://doi.org/10.1 007/s00068-006-5065-x

Hoff WS, Holevar M, Nagy KK, Patterson L, Young JS, Arrillaga A, Najarian MP, Valenziano CP (2002) Practice management quidelines for the evaluation of blunt abdominal trauma: the east practice management guidelines work group. J Trauma 53(3):602-615. https://doi.org/10.1097/00005373-20020900000038

lerardi AM, Duka E, Lucchina N, Floridi C, De Martino A, Donat D et al (2016) The role of interventional radiology in abdominopelvic trauma. Br J Radiol 89(1061):20150866. https://doi.org/10.1259/bjr.20150866

Karamercan A, Yilmaz TU, Karamercan MA, Aytaç B (2008) Blunt abdominal trauma: evaluation of diagnostic options and surgical outcomes. Ulus Travma ve Acil Cerrahi Derg 14:205-210

Leppaniemi AK, Mentula PJ, Streng MH, Koivikko MP, Handolin LE (2011) Severe hepatic trauma: nonoperative management, definitive repair, or damage control surgery? World J Surg 35(12):2643-2649. https://doi.org/10.1007/s002 68-011-1309-y

Lopera JE (2010) Embolization in trauma: principles and techniques. Semin Intervent Radiol 27(01):014-028. https://doi.org/10.1055/s-0030-1247885

Matthes G, Stengel D, Seifert J, Rademacher G, Mutze S, Ekkernkamp A (2003) Blunt liver injuries in Polytrauma: results from a cohort study with the regular use of whole-body helical computed tomography. World J Surg 27:11241130. https://doi.org/10.1007/s00268-003-6981-0

Monnin V, Sengel C, Thony F, Bricault I, Voirin D, Letoublon C, Broux C, Ferretti G (2008) Place of arterial embolization in severe blunt hepatic trauma: a multidisciplinary approach. Cardiovasc Intervent Radiol 31(5):875-882. https:// doi.org/10.1007/s00270-007-9277-1

Monsignore LM, Scarpelini S, Santos JS, Abud DG (2012) Urgent percutaneous transcatheter embolization of hemorrhagic hepatic lesions with $\mathrm{N}$-butyl cyanoacrylate. Diagnostic Interv Radiol 18:403-409

Niimi Y, Berenstein A, Setton A (2003) Complications and Their Management During NBCA Embolization of Craniospinal Lesions. Interv Neuroradiol 9(Suppl 1):157-164. https://doi.org/10.1177/15910199030090S122

Papakostidis C, Kanakaris N, Dimitriou R, Giannoudis PV (2012) The role of arterial embolization in controlling pelvic fracture haemorrhage: a systematic review of the literature. Eur J Radiol 81(5):897-904. https://doi.org/10.1016/j.ejrad.2 011.02.049

Petrowsky H, Raeder S, Zuercher L, Platz A, Simmen HP, Puhan MA, Keel MJ, Clavien PA (2012) A quarter century experience in liver trauma: a plea for early computed tomography and conservative management for all hemodynamically stable patients. World J Surg 36(2):247-254. https://doi. org/10.1007/s00268-011-1384-0

Ptohis ND, Charalampopoulos G, Abou Ali AN, Avgerinos ED, Mousogianni I, Filippiadis D et al (2017) Contemporary role of embolization of solid organ and pelvic injuries in Polytrauma patients. Front Surg 4:2-7 Available from: http://journal.frontiersin.org/article/10.3389/fsurg.2017.00043/full

Raikhlin A, Baerlocher MO, Asch MR, Andy Myers M (2008) The Splenic embolization in trauma diagnosing and grading splenic injuries. Can I Surg 51:464-472

Rezende Neta DS, Alves AK e S, de Leão GM, de Araújo AA (2012) Perfil das ocorrências de politrauma em condutores motociclísticos atendidos pelo SAMU de Teresina-PI. Rev Bras Enferm 65:936-941

Sabe AA, Claridge JA, Rosenblum DI, Lie K, Malangoni MA (2009) The effects of splenic artery embolization on nonoperative Management of Blunt Splenic Injury: a 16-year experience. J Trauma Inj Infect Crit Care 67(3):565-572. Available from: http///content. wkhealth.com/linkback/openurl?sid=WKPTLP:landingpage\&an=00005373-20090900000022. https://doi.org/10.1097/TA.0b013e3181b17010

Smith J, Caldwell E, D'Amours S, Jalaludin B, Sugrue M (2005) Abdominal trauma: a disease in evolution. ANZ J Surg 75(9):790-794. https://doi.org/10.1111/ j.1445-2197.2005.03524.x

Stassen NA, Bhullar I, Cheng JD, Crandall M, Friese R, Guillamondegui O et al (2012) Nonoperative management of blunt hepatic injury: an eastern association for the surgery of trauma practice management guideline. J Trauma Acute Care Surg 73(5 Suppl 4):S288-93 
The ATLS Subcommittee, American College of Surgeons' Committee on Trauma, and the International ATLS working group, Chicago I (2013) Advanced trauma life support (ATLS ${ }^{\circ}$. J Trauma Acute Care Surg 74:1363-1366 Available from: http://insights.ovid.com/crossref?an=01586154-20130500000026

van der Wilden GM, Velmahos GC, Emhoff T, Samielle Brancato M, Adams C, Georgakis G, Jacobs L, Gross R, Suresh Agarwal M, Burke P, Maung AA, Johnson DC, Winchell R, Jonathan Gates M, Cholewczynski W, Rosenblatt M, Yuchiao Chang P (2013) Successful Nonoperative Management of the Most Severe Blunt Liver Injuries A Multicenter Study of the Research Consortium of New England Centers for Trauma. Arch Surg 147:423-428

Wahl WL, Ahrns KS, Chen S, Hemmila MR, Rowe SA, Arbabi S (2004) Blunt splenic injury: operation versus angiographic embolization. Surgery. 136(4):891-899. https://doi.org/10.1016/j.surg.2004.06.026

Wallis A, Kelly MD, Jones L. Angiography and embolisation for solid abdominal organ injury in adults - a current perspective. World J. Emerg. Surg. 2010

Wei B, Hemmila MR, Arbabi S, Taheri PA, Wahl WL (2008) Angioembolization reduces operative intervention for blunt splenic injury. J Trauma - Inj Infect Crit Care 64(6):1472-1477. https://doi.org/10.1097/TA.0b013e318174e8cd

Whitaker I, DE Gutiérrez M, Koizumi M (1998) Gravidade do trauma avaliada na fase pré-hospitalar. Rev Ass Med Bras 44(2):111-119. https://doi.org/10.1590/ S0104-42301998000200008

Zealley IA, Chakraverty S (2010) The role of interventional radiology in trauma Source BMJ Br Med J 340:356-360 Available from: http://www.jstor.org/sta ble/25674003

\section{Publisher's Note}

Springer Nature remains neutral with regard to jurisdictional claims in published maps and institutional affiliations.

\section{Submit your manuscript to a SpringerOpen ${ }^{\circ}$ journal and benefit from:}

- Convenient online submission

- Rigorous peer review

- Open access: articles freely available online

High visibility within the field

- Retaining the copyright to your article

Submit your next manuscript at $\boldsymbol{\nabla}$ springeropen.com 